\title{
A Lucta contra o Delicto
}

Não obstante as modificações que soffreram as idéas sobre a repressão dos crimes no fim do seculo XVIII, e no decurso do ultimo, a verdade é que os processos legaes em tal assumpto são os mesmos archaicos, e reconhecidos como pouco efficazes para a defeza da sociedade. As revoluções, e não evoluções, na parte doutrinal foram de vulto, mas nas leis não se interrompeo a tradição, recebidas apenas leves alterações indicadas pelos reformadores.

Tres foram as grandes epochas da sciencia penal nestes ultimos tempos: I.$^{0}$ a da sympathia pelo criminoso, considerado um infeliz transviado por não tẹ sido educado, e havido como susceptivel de correç̧ão; $2 .^{\circ}$ a da ferocidade contra o criminoso, julgado um monstro, variedade do genero humano, o homo delinquens, a calhar em qualquer hypothese para soffrer a pena de morte, que os sabios só não recommendavam como applicavel sempre por uma concessão ao sentimentalismo do vulgo profano; $3 .^{\circ}$ a da critica, que, reconhecendo a verdade de alguns conceitos estabelecidos na 2. ${ }^{a}$ epocha, repelle entretanto os exageros em que cahiram os jurisconsultos daquelle tempo. Alguns 
contestam a existencia desta nova eschola, e a consideram uma continuação ou modificação da $2 .^{a} \mathrm{Ha}$ quem a considere desenvolvimento da classica. (Alimena v. I, pag. 27). A abundancia de novas idéas sobre os meios de repressão do crime; a repulsa do conceito fundamental de ser o delinquente uma reapparição por atavismo do homem primitivo, conceito que servio de cimento para se formularem quasi todos os principios da eschola anthropologica; a applicação quasi exclusiva pela eschola anthropologica das sciencias medicas para o estudo das sciencias juridicas, ao passo que a nova eschola reivindicava todos os direitos da philosophia juridica no estudo do crime, o mais dramatico phenomeno social, todas essas profundas divergencias e muitas outras, autorizam a classificação das doutrinas sustentadas nesses ultimos tempos como constituindo uma nova eschola, a que se tem dado varios nomes, como sejam critica, sociologia, terza scuola (Alimena v., I pag. 26 e segs.), etc.

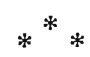

Antes de tudo, é preciso que saibamos que vamos fugir quanto possivel ás preoccupações de estudos de gabinete.

Não nos sujeitamos ás licções de mestres, quaesquer que sejam ellas, quando em contrario á nossa observação. Em todas as sciencias e artes ha uma série de erros seculares e escholares, que se encontram em quasi todos os livros, cujos autores se copiam uns aos outros. Invocamos para nos ser concedido este direito a mesma autoridade que tem o clinico que về directamente ao infermo, e que, á vista 
dos phenomenos observados, contésta aos mais sabios mestres.

Exemplificaremos. Contam que o maior clinico brazileiro acompanhado de seus alumnos, examinava os doentes de um hospital, e diagnosticou para um destes tuberculose no ultimo periodo, receitando pilulas de cynoglossa como calmante para mitigar os derradeiros momentos de vida do infeliz. Succedeu que dias depois o infermo começou de apresentar melhoras, e um irreverente discipulo chamou para isto a attenção do mestre, que viu nos bons symptomas o ultimo tremular da lampada que se apaga. O alumno não era porém escravo do magister dixit, e diligenciando por descobrir a chave do enigma, veio a conhecer que, por um feliz erro o infermeiro mandára aviar pilulas de Belloste, acertando no medicamento conveniente, pois o infermo tinha syphilis!

Quanto clinico illustre sob o nome de Lombroso organiza o celebre arlequim, hoje objecto de risóta até de alguns sensatos e guedelhudos subdelegados sertanejos, quanto Garofalo descobre um ar de parentesco entre os mais dispares typos physionomicos de delinquentes!

Uma observação fria durante mais de um quarto de seculo da vida nas prisões, habilita a quem escreve essas linhas a contestar assertos de mestres, que conhecem os delinquentes pelas descripções dos livros, ou por vel-os durante alguns minutos nas salas dos tribunaes, e sabem do crime pelas ornadas e romanticas narrativas dos advogados e das gazetas.

Juiz do crime em comarca sertaneja, homizio de criminosos, como foi a de Jaboticabal em i886, e depois na culta e populosa Campinas, advogado acompanhando de perto a vida dos delinquentes, e o des- 
dobramento de todos os delictos em comarca cuja cifra de crimes rivaliza com a Capital deste Estado, qual a de Ribeirão Preto, acha-se o autor destas linhas apto para muito dizer sobre os meios de cohibir o desenvolvimento da criminalidade.

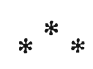

Vejamos quaes os fundamentos da pena. Longe de nós qualquer idéa de expiação, ou outra equivalente. Partimos do positivo conceito de que todos queremos viver, e que a sociedade tem como dever primordial assegurar a vida aos membros de que se compóe.

Mas não basta viver, ha certos casos em que outros b̀ens são mais importantes que a propria vida. Como explicar o suicidio sinão deste modo?

A honra por exemplo, ou melhor a estima publica, é geralmente muito mais valiosa que a propria vida. Theologos e medicos, que desconheceram ésta verdade, cahiram nos mais lamentaveis erros. Assim, nos annaes dos crimes em França, encontramos a inutil lucta travada pelo Cardeal Richelieu contra o duello (aliás em certa epocha adoptado pela Egreja), e vemos as mais lastimaveis execuções capitaes de fidalgos uteis á patria, e sacrificados pelo fanatismo do ministro de Luiz XIII. Berryer conserva, nas Liçôes de Eloquencia, as paginas immorredouras, em que se descrevem essas crueldades, incapazes de desarraigar dos costumes francezes o duello que só por uma melhor distribuição de justiça e por uma transformação na opinião publica hâ de desapparecer do numero dos flagellos da nobreza de França (FERrI, Sociologia, pag. 432 n. ${ }^{a}$ 4). O "propter vitam vivendi perdere causas» não é uma elegante formula poetica, 
é uma verdade fundamental, que deve ser sempre presente os jurisconsultos.

Os medicos, em cujo numero ponho em evidencia Lombroso e Ziino, esqueceram-se de que prospectiones funt e turribus, e, habituados a só tratarem $\mathrm{da}$ conservação da vida e da saúde, não abrangeram com vista larga todos os bens que a sociedade é destinada a realizar. (Dr. J. Hygino, Int. a $V$ Listz, pag. 37 ).

Assim, consultados sobre o modo de extinguir as molestias epidemicas neste Estado, nenhuma medida havendo ainda na sciencia, recommendaram o antigo isolamento, a anachronica quarentena com todos os seus horrores. Que a sociedade deve se defender do pestoso é o que sabe qualquer caboclo da mais rudimentar cultura, mas que seja licito queimar vivo o varioloso no seu proprio leito, depois de bem amarrado, eis o que o mesmio sertanejo refere com horror $e$ reprovafão ter-se feito em paragens, onde os principios adoptados nos centros civilizados deste Estado foram levados ao extremo. Ao proclamar um principio de bom effeito para a saúde publica, devemos attentar nos males sociaes que resultam de sua applicação. Nesta capital ao tempo da primeira irrupção da peste bubonica, tomada de panico a população, acceitou $o$ isolamento incondicional nos nossos pessimos lazaretos, pessimos ao menos sob o aspecto da moralidade, pois são notorios os attentados ao pudor de que têm sido victimas pessôas a elles recolhidas, mas por felicidade foi uma das primeiras victimas da peste pessôa altamente collocada. Cahiram os medicos na conta, e no dia immediato o mais autorizado dizia pelos jornaes que não se podia lançar a todos na promiscuidade pecuária de um lazareto.

Foram estas duas as expressões empregadas pelo Dr. Luiz Barretro, e que muito agradaram a todos. 
Nem é original a opinião que vimos sustentando neste exemplo. A campanha em França e noutros paizes cultos contra o isolamento por syphilis, embora restringida a um insignificante numero de infelizes tem provocado os mais vivos protestos. Ainda ha poucos annos, lemos na Grande Revue um magistral artigo contra o isolamento de Saint-Lazare.

Felizmente não se levou a effeito o plano de instituir um juizo sanitario, o que seria prova de completa falta de juizo dos nossos legisladores. Não co. nhecem os medicos o "Integram sapientiam excolite, rationem humanam universam perficite."

Deixando a analyse da influencia damnosa dos medicos no estudo das materias sociaes por terem attendido a um unico interesse social, passaremos a mostrar quanto mal trouxeram os preconceitos religiosos. Não queremos fallar da doutrina exposta por Carrara, e tão habilmente dissecada por Puglia. Numa sessão do jury, expunha o Dr. Francisco DA Costa Cakvalho, o mais recto caracter que temos conhecido, que o accusado praticára um delicto em desaffronta da honra. Obtemperou na réplica o promotor que tal circumstancia era attenuante, e não justificativa ( $\mathrm{I}$ ). Treplicou o venerando e leal advogado

(1) E' sabido que, em 1889, era corrente na jurisprudencia que a desaffronta não se achava comprehendida na defeza dos direitos de que fallava o art. $14 \S 2$. Dizião: $10^{\circ}$ que, tendo cessado o ataqne no nomento da desaffronta, era ella vingança, e não acto de defeza; $20^{\circ}$ que (ampliação do $1:^{\circ}$ ) não se dava o requisito da falta absoluta de outro meio menos prejudicial; porque havia os recursos legaes; $3 .^{\circ}$ que a desaffronta estava comprehendida entre as attenuantes no art. 18 \& 4 . E' certo qụe respondiam os adversarios: $10^{\circ}$ que $o$ ataque ao direito que temos á estima publica perdurava até que pela desaffronta recuperassemos tal direito $; 2 .^{\circ}$ que nem sempre os meios judiciaes nos restituem a estima publica; e $3 .^{\circ}$ que a attenuante do art. $18 \S 4$ apparecia, quando faltava algum dos requisitos da defeza. O certo é que prevaleceo a $1 .^{\mathrm{n}}$ ópiniâo. Digamos de passagem que os arts. $32 \S 20$ e $42 \S 2$ do novo codigo de 1890 deixam as mesmas duvidas. 


\section{$-7 \dot{3}-$}

declarando que estava longe de querer illudir ao jury; que com effeito a desaffronta. era uma attenuante, mas que de qualquer fórma que fosse a lei, estava na consciencia de todos que o réo não merecia a pena, e por isto elle, na qualidade de defensor pedia que se formulasse o quesito sobre a circumstancia que mais analogia tinha com a desaffronta que era pelo Codigo de I830, o então em vigor, a loucura. E o réo foi absolvido unanimemente. Conclúe-se dahi que o legislador de I830 não attendeu a todos os interesses sociaes no momento historico em que formulou o Codigo Penal. Esqueceu-se de que os principios do christianismo não haviam alterado a opiniẫo que os homens têm da honra e da vida. A lei penal deve attender a tudo isso, e não ser filha de prejuizos de seitas, quer scientificas, quer religiosas. Todos os direitos dos membros da sociedade, todos os interesses da communhão devem ser tidos em consideração.

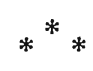

Si a pena deve sempre ser decretada tendo-se attenção a todos os interesses e bens sociaes, claro é que terá um limite que não póde ser determinado $a$ priori, mas que o conhecimento do estado social por um sabio legislador será sufficiente para definir (AliMENa v. I, pg. 24; Dr. J. Hygino, Intr a Von Listz, pg. XL.) Já não queremos pôr este limite no sentimento de justiça de que falla Alimena (v. I, pg. 24), mas ninguem nos contestará seriamente que os interesses dos individuos em sociedade dictam taes restricções, que estão na consciencia de todos.

$$
*^{*} *
$$


Só pode haver um criterio para a applicação das penas, e é a defeza social, cujo unico limite é o direito individual, que não julgamos opposto á ordem social, quando devidamente apreciado.

Só ha um verdadeirı delinquente: é o que constitúe uma ameaça para a ordem social. Principal funç̧ão da pena é pois segregar da communhão dos bons o membro perigoso, isto porém com as restriccões que acima demos, e que podem ser contidas na feliz formula de Guyau: a pena deve attingir o maximo de defeza social, com o minimo de soffrimento individual (v. I, pg. 23). E' certo que Alimena appella para o vago sentimento de justiça, e nós para a conveniencia social, segundo a opinião geral, mas de accordo nos achamos com o grande criminalista em que não se póde eliminar o deliquente para bem da sociedade, como se corta o galho de uma arvore (v. I, pg. Io).

Mas ésta principal funcção da pena se applica ainda ao loucn e ao pestoso? Sim, uma vez que haja meios de isolar, que não ataquem aos sentimentos, interesses ou conveniencias dos demais membros da sociedade. Ninguem quer estar numa sociedade em que a desgraça de ser affectada por uma molestia mental ou contagiosa seja motivo de imposição de medidas vexatorias. Eis porque o isolamento do infermo deve ser com o maior bem estar para elle, ao passo que esse bem estar será restringido na pena, querendo-se alcançar o segundo effeito, que é a intimidação dos que não praticaram delictos. Esta segunda funç̧ão da pena, que era chamada a defeza indirecta é de impờrancia tão grande quanto a primeira.

A pena precisa actuar como motivo determinante na consciencia dos homens, como a ameaça de um soffrimento (Alimena v. I., pg. I7). Até certo ponto 
tẹm razão ZIıNo, quando diz que a penitenciaria deve ser um logar de dôr e de soffrimento. O temor da pena deve actuar nọ espirito dos que ainda não commetteram o delicto como um motor mais forte que o impulso á violação da lei: "é um motivo sensivel contraposto ao delicto", segundo Beccaria (Al. v. I, pg. I 5). Pretender porem refinar as torturas do carcere, porque ainda ha quem diga, segundo Zirno, que na cadeia está melhor do que no trabalho livre, é desconhecer completamente o que é a vida do preso. A phrase referida por Ziıno não é mais que uma bazofia, em que só podem crer os que não sabem o que é o amor á liberdade, sabios estiolados nos estudos de gabinete. Ah! si soubesse ZiINo quantos escravos se suicidaram, por preferirem perder a vida a mantel-a na escravidão, não acreditaria que haja prisão preferivel á mais dura, e mais miseravel das vidas!....

Esta segunda funç̧ão da pena é inapplicavel ao louco e ao doente: "o louco é intimidavel, mas não o são os loucos» (Alimena v. i, pg. I 4).

Neste ponto apresenta-se na prática uma das mais difficeis questões, e vem a ser a de determinar as verdadeiras raias da loucura, materia ainda embaraçada pelo reconhecimento da zona neutra, e pela questão da responsabilidade parcial dos loucos.

A difficillima questão do estabelecimento das lindes do terreno da loucura é exclusivamente prática. Em theoria o assumpto escapa completamente á sciencia criminal: tem a mão a sciencia medica para dizer a esse respeito.

Ainda admittindo a zona neutra, não podemos concordar com a responsabilidade parcial do louco. Uma vez que ha duvida sobre o estado de saúde mental do réo, a pena, tal como foi por nós deter- 
minada, isto é, um soffrimento imposto ao réo para exemplo dos demais membros da sociedade, deixa de ser um elemento de intimidação. Não nos venham accusar de sentimentalismo. Ainda admittindo que o louco seja insensivel ao soffrimento, e que seja tão infeliz de ser louco quanto o cavallo por não saber grammatica, segundo Erasmo (Allmena v. 2, pg. I3), entretanto seus parentes, amigos e todos os homens de coração bem formado soffrem pelos máus tractos infligidos aos loucos.

Digamos de passagem que o louco soffre, e é sensivel aos máus tractos, segundo nos parece, mas é aqui o logar em que ainda uma vez daremos a mão á Medicina.

A funç̧ão correctiva da pena é tão difficilmente realisavel, que nos parece inutil della nos occuparmos.

$$
*^{*}{ }^{*}
$$

Não podemos porém estudar a materia criminal só pelo aspecto que nos apresenta o crime. Cumpre tambem analysar o criminoso. Deixaremos for completamente contrária ás verdadeiras doutrinas criminaes, a classificação de FERRI, e adoptaremos a de VoN Listz, que aponta dois typos de delinquentes: os da criminalidade aguda e os da chronica. Põe em evidencia que dois grupos de factores concorrem para o crime: a natureza individual do delinquente, $\mathrm{e}$ as relações exteriores ou sociaes, e especialmente as relações economicas. Diz então: "I.$^{\circ}$ As circumstancias exteriores que dão causa ao crime preponderam. Arrebatado por uma excitação repentina e apaixonada, ou sob a influencia de uma oppressiva necessidade, o agente, até então irreprehensivel, com- 
mette o crime que, alheio á sua indole, se apresenta como um episodio isolado na sua vida, e amargamente lamentado (o crime de occasião, como o denominam com pouca propriedade: criminalidade aguda). $2 .^{\circ}$ Dada uma occasião externa futil, o crime resalta, digamos assim da indole, das dispošições arraigadas do delinquente, e nos revela a sua natureza intima. Rudeza brutal, crueldade destituida de toda sensibilidade, estupido fanatismo, descuidosa leviandade, invencivel repugnancia ao trabalho, desregrada sensualidade, levam o agente por numerosas phases de transição a situações indubitavelmente- psychopathicas». De fóra parte a affirmação de psychopathia inexplicavel para nós nessa classificação de VON Listz, é ella quanto ao mais mais acceitavel. Os criminosos o são, em summa, ou accidentalmente ou por caracter. Nos primeiros a pena actúa segredando e corrigindo, porque, si fossem deixados na sociedade, é de temer passassem pelo habito á segunda cathegoria, mas ainda é nelles efficacissima a pena como meio de intimidação social. Nos segundos é importantissima a primeira funcção da pena: a segregação.

Como não é de esperar que se corrijam, ainda pela lembrança do mal da pena que experimentaram, e de que não têm simples representação, pouco podemos contar com o effeito da punição delles, depois de terem cumprido a pena, e serem postos em liberdade. São estes os reincidentes. Si por um lado desanimam ao criminalista que vê pela reincidencia a inefficacia da pena, por outro animam por serem em pequeno numero, acantoando dest'arte o crime numa parte muito restricta do corpo social. Alimena é do numero dos que ligam grande importancia á reincidencia, porque o reincidente "mostra che il delitto non $\grave{e}$. un episodio della sua vita, ma è qualche cosa che trova la sua base nella sua stessa indole.» (V 3, pg. 57 I). 


\section{$-78-$}

A reincidencia mostra a inefficacia da pena, ainda aggravada. A aggravação e o variar de pena não darão provavelmente os resultados esperados pela eschola positiva (F LORIAN, pg. 369), mas as medidas de caracter policial poderão ser efficacissimas, quando se constituir uma policia capaz, como abaixo diremos. $\mathrm{E}^{\prime} \mathrm{o}$ que indica Merkel, segundo o Dr. J. Hygino (Von Listz, v. I, pg. 449 n. A).

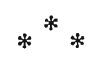

Da pena pouco mais podemos esperar do que o que tem dado: a conservação em estado estacionario da média da criminalidade. Já é bastante. Nem cremos que os homens tenham melhorado ou peiorado com o progresso da humanidade, no que acompanhamos a AcHilles Loria, nem confiamos nas estatisticas, que mostram augmento ou diminuição da criminalidade. Os trabalhos estatisticos não existiam antigamente, e hoje são ainda imperfeitissimos. A julgarmos porém pelos ultimos annos, em que estes trabalhos tem se feito com mais cuidado, cremos indispensaveis os substitutivos penaes. Importantissima é a obra de $\mathrm{G}_{\mathrm{A}}$ ROFALO na parte referente ás leis preventivas do crime.

Mas a funcção preventiva ha de ser confiada á policia, e isto que possuimos sob tal nome nem merece classificação. A chamada policia de carreira é mil vezes peior que a antiga dos coroneis. Conta Machiavel que para se executar um assassinato dentro de uma egreja foram chamados sacerdotes, afim de que ñ̃o ficassem no momento do crime impressionados. 
Foi o que se deu com a policia deste Estado. A antiga tinha medo da responsabilidade, mas a nova composta de bachareis descrentes, e que conhecem a relaxação geral, que actualmente ha na nossa sociedade, não recúa diante de nenhum abuso, de nenhuma violencia. Não queremos aqui registar factos deprimentes para os nossos fóros de povo civilizado praticados pela nòssa policia: já bastam as tristes verdades postas em circulação pelos jornaes estrangeiros aqui publicados. Só nos resta por consolo que, embora a peior do mundo, não é a unica ruim: por toda a parte a policia é má. $\mathrm{Na}$ descoberta dos crimes a policia é a tyrannia, e tyrannia inutil.

Vimos ha dias a noticia da traducção do allemão para o espanhol do Manual do Fuiz. Pelas epigraphes notámos que grande parte do livro se destina á caça dos criminosos. Ora, as proezas do Snr. Vidocq, a sagacidade da policia franceza, só existem nos romances, ou nas anecdotas dos rastaquéres, que querem nos deslumbrar com coisas phantasmagoricas da encantada Paris. Todos conhecemos a opinião daquelle sensato inglez para o caso de ser accusado em Paris de haver furtado o Arco do Triumpho, e escondido o monumento na algibeira. Aqui, acompanhando de perto todas as descobertas de crimes, podemos assegurar que nenhuma dellas foi devida a diligencias policiaes, mas sim a denuncias de inimigos do culpado ou de espiritos inclinados á malsinação, de que é o numero elevadissimo.

Poucas pessôas sabem quão avultada é a quantidade de denunciantes no nosso meio actual. Pinheiro Ferreira combatia a policia secreta, por tolher tal instituição ao individuo a franqueza, que deve existir nas sociedades. $O$ motivo é improcedente: temos visto centenas de denuncias gratuitas. Queremos che- 
gar á conclusão: para a policia não precisamos exigir faro no funccionario, mas basta que elle espere e receba a collaboração popular na descoberta dos delictos. Parece um paradoxo isto, mas é uma verdade colhida de longa experiencia nossa. Illudido andáá quem acreditar nas narrativas de caçadas miraculosas de criminosos. Policia de carreira caçadora tem ainda o inconveniente de forjar crimes, e fabricar falsas provas, com o intuito unico de promoções para os funccionarios, como succede, segundo ouvimo dizer, em Paris.

A realidade é que a nossa policia ainda trabalha como no tempo do livro quinto das Ordenações: Apresentada a certo delegado do interior uma queixa resolveu elle illico mandar pegar tres ou quatro suspeitos, e submettel-os a uma surra para confessarem o crime. Observando o queixoso que a medida era extrema, retorquic o funccionario: "Mas que quer então que eu faça? Por bem elles não confessam. E não é illegal, porque o doutor que veio da capital para aqui como delegado em commissão por parte do governo assim fez, e diz que é uso em S. Paulo, e muito legal porque a constituição de 1822 que prohibia a applicação de tratos foi revogada pela de I89 I que nada diz ao proposito"! $\mathrm{O}$ delegado era um espirito logico, franco quanto HobBes, e que guardava o systema que víra empregado pelos senhores de escravos, que por sua vez tinham aprendido com os juizes do crime: a lava de $\mathrm{I} 789$, á semelhança da do Vesuvio em Pompea, tudo conservou, em vez de tudo destruir, como geralmente se pensa.

$\mathrm{Si}$ pudessemos conseguir pessoal instruido e moralizado na policia, ésta instituição seria efficacissima para a prevenção dos delictos. Traria sob suas vistas todos os criminosos que já houvessem cumprịdo sen- 
tença, e os individuos que, por seu máo procedimento moral, se mostrassem como estando na imminencia de incidir na lettra da lei penal.

Aqui é logar propicio para observarmos que um grancle crime nunca deixa de ser precedido de outros pequenos, que passam despercebidos aos olhos das auctoridades. Liga-se pouca importancia ás irregularidades de vida de alguns individuos, que estão sempre em rélações com a policia, quando é seguro que são estes os que formam mais tarde a legião dos grandes criminosos.

Uma bôa policia é para nós um dos primeiros recursos para ser conseguida a diminuição dos crimes. Confessamos porém que, embora facil conseguir uma melhor do que a mais que pessima actual, não deixa de ser difficil alcançar outra bôa. Já fizemos sentir que não ha necessidade de recorrer a ferozes caçadores de criminosos, bastando que os funccionarios se limitem a acceitar a collaboração do publico. Temos de accrescentar que a policia deverá ser composta de funccionarios assaz instruidos para que não se encolerizem contra o crime, que é um phenomeno fatal (FERri, Soc. n. $4 I$, pg. $464,4 .^{\mathrm{a}}$ ed.); que comprehendam qual o respeito devido aos direitos individuaes, nomeadamente á dignidade e á liberdade; que sejam activos, e, mais que tudo, que não esperem promoção pelos actos que praticarem, que são tão faceis de serem phantasiados, quanto em geral os de todos os caçadores. Ésta ultima observação cae-nos dos bicos da penna, tendo nós em lembrança diversos inqueritos feitos neste Estado, que nada ficam a dever aos servifos politicos parisienses, contra os quaes clama agora a imprensa por terem levado a victima ao patibulo e o autor á cumiáda do poder. As mais das vezes os honrados e pacificos paes de familias nomeados 
para cargos policiaes se transformam em feras, porque tomam a peito, por ignorancia, extinguir a criminalidade. Chegam ao mesmo resultado que os actuaes funccionarios policiaes de carreira; mas por outros motivos.

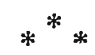

A Ferri, mais que a qualquer outro, devemos o estudo dos meios de luctar contra o crime, deixando a pena como um recurso extremo, de que nada mais podemos esperar que o resultado já obtido. Denominou-os sostitutivi penali (n. $3^{8}$ ).

Em sua generalidade são privações impostas aos que desejam a manutenção da ordem para que não seja dada occasião de incidirem na lei penal os que não querem concorrer para a realização dos fins sociaes: emprego da moeda metallica de preferencia ao commodo papel, que é mais sujeito á falsificação, abolição das festas, em que os gatunos acham circumstancias propicias para as suas inclinações, etc. Estes parecem-nos inacceitaveis: não convém sacrificar os bons aos máos, além do mais porque os máos procurarão outras opportunidades para exercerem sua acção perniciosa. Ha porém alguns sostitutiv recommendaveis, e entre elles enumeraremos: o divorcio para evitar o adulterio, diversos institutos para a protecção das mulheres gravidas, afim de se evitar $o$ infanticidio, etc.

São porém todos os recursos indicados por FERRI sujeitos á contra prova da experiencia, para poderem ser apreseirtadas como realmente efficazes.

O que nós asseguramos por observação propria, é que ha no Brasil tres causas principaes dos grandes delictos, a saber: ${ }^{\circ}{ }^{\circ}$ alcoolismo, $2 .^{\circ}$ vadiagem, e $3 .^{\circ}$ porte de armas. 
a mais complexa em sua origem, e a que mais difficilmente sérá combatida, a primeira. FerrI aponta como factores do alcoolismo: a necessidadè que têm os pobres de um excitante para o trabalho forçado a que devem se entregar, a de um consolador de tristezas e a de um aquecedor para supprir a falta de vestes sufficientes contra o frio europeu.

Outros autores têm indicado outros motivos de menor importancia, entre os quaes o desejo de obter um certo bem estar após as parcas refeições (eupho. ria). Os incentivos ao alcoolismo indicados por FERRI são os geralmente acceitos.

Lastimamos ter de mostrar que taes opiniões não passam de reproducção de um erro, que se vae repetindo, sem completo exame de todas as condições em que apparece o mais tremendo flagello da humanidade. Aqui no Brasil bebem os operarios tanto quanto na Europa para augmentar sua alegria, para acalmar a agitação resultante do uso do café (que menos apreciam), e para refrescar. Si estas linhas cahissem sob as vistas de FERRI, julgaria elle que estamos a zombar, e no emtanto não ha no Brasil quem ignore que é séria, muito séria ésta ultima phrase, e vulgarissima, embora sempre repetida em tom de mófa pelos que não são devotos de Baccho. Ora, si nos grandes centros agricolas, na epocha da maior prosperidade, quando, segundo observação de um assiduo frequentador das sessões do jury, não apparecia réo sem defensor pago, os operarios desprezavam a mais excellente dentre as bebidas estimulante das forças abatidas; o café, para procurarem o alcool; si, não tendo necessidade de agasalho, nem de consolo, passando mais da metade da semana em férias, tendo dinheiro em abundancia, sem preoccupaçổes, mantinham mais alta do que nunca a porcentagem 


\section{$-84-$}

de consumo do alcool, como esperar remedio contra o alcoolismo na melhora das condições do operario?

Deveriam FERRI e outros ter feito investigações nas classes operarias que não as europeas, mas forçoso nos é reconhecer que isto nãu lhes era facil. Imperdoavel porém é que não estudassem as classes altas europeas.

Qual o motivo do alcoolismo entre as pessôas da bôa sociedade europea?

FOREL aconselha as pessoas cultas a não beberem nem moderadamente, para não darem mau exemplo às classes rudes, que não sabem qual o ponto em que o uso passa a abuso. Condemnamos o remedio já por ser um sacrificio imposto aos bons em favor dos maus, já porque temos observado que é absolutamente inefficaz: não é raro observarmos a embriaguez entre os empregados de pessoas abstemias.

Resta só a punição da embriaguez, auxiliada por meios empiricos de pequeno effeito, dos quaes ainda o melhor é o imposto sobre as bebidas com isenção de direitos sobre as inutilizadas para outros fins que não os industriaes.

A pena contra a embriaguez precisa ser indefectivel como ensina Garofalo, de modo que não tenha o ebrio a esperança de escapar á condemnação. Sendo a embriaguez um facto facil de se verificar, parece-nos que com simplissimas formulas se poderia chegar ao fim do processo, sem as delongas necessarias ás causas por crimes de mais difficil apreciação.

O segundo factor importante dos crimes é a vadiagem. Quando a produç̧ão abundante do café na região do Oeste deste Estado, e a alta do genero, determinaram enorme elevação de salarios, não era raro que os trabalhadores procurassem pessoas lettra- 
das para saberem durante quantos dias na semana ou no mez precisavam se occupar afim de terem o conforto a que estavam habituados, e dedicarem ao ocio e á embriaguez o resto do tempo.

$O$ vadio, além de ser um dos maiores contribuintes para o augmento da criminalidade, é pezadissimo ás classes laboriosas. É elle que enche os hospitaes, que occupa sem pagar aos medicos, advogados e pharmaceuticos, os quaes por sua vez vivem das classes laboriosas, que, ainda depois de morto, incommoda a sociedade com o enterramento, pago pelos trabalhadores. O dever juridico de trabalhar é pois materia de tomo.

Resta o porte de armas. As leis modernas, naturalmente sob o influxo de que era um dos direitos da aristocracia antiga o porte de armas, têm sido pouco severas contra este mau habito. Concorre tambem para tão perigoso costume a falta de energia das autoridades policiaes, quasi sempre dependentes de chefes politicos poderosos, protectores de capangas. E' um mal que será evitado quando tivermos policia.

Uma das medidas que provavelmente mais abrandarião os effeitos da vadiagem, do alcoolismo e do porte de armas seria a abolição do domingo, como dia de repouso geral, concedendo cada estabelecimento qualquer outru dia de descanço na semana, de modo a reduzir-se de $\overline{5} / 6$ as reuniões dos ebrios e ociosos, que hoje se dão nos domingos.

Entre as causas de incitação ao crime tem-se fallado da benevolencia do jury, e ultimamente até da corrupção desse tribunal.

Não é de nenhum modo nossa intenção reproduzir os argumentos pro e contra o instituto, nem 
haveria utilidade, tão conhecida é a materia (FERRI, Soc. n. ${ }^{\text {os }} 80$ e seguintes). Queremos só assignalar que poucos dias depois de ter sido publicado num jornal do Rio de Janeiro um artigo, attribuido a certo desembargador, contra o jury, apparecia num jornal de São Paulo outro artigo, em que se formulavam as mesmas queixas e mais outras contra os juizes togados. Ora, si, nas poucas causas criminaes que lhes tém sido confiadas, os juizes togados brasileiros têm andado muito peior que o jury, como faremos a imprudencia de abolir ésta instituição para entregarmos a nossa vida, a nossa liberdade e a nossa honra a juizes que têm dado pessima conta dos encargos, que lhes têm sido confiados? Justiça humana é isto mesmo: não busquemos o impossivel.

Admittindo que o jury seja corrupto (e argumenta-se com um facto singular occorrido no Rio de Janeiro), que podemos esperar dos magistrados que tambem sahem dessa mesma sociedade que o jury. representa?

Nossa opinião é que o jury brasileiro longe de ser, como dizem alguns maniacos da moda, uma pessima instituição, é um soffrivel tribunal, o melhor mesmo na actualidade. Não negamos que tenha defeitos. Não contestamos que deva ser melhorado. Até nos parece que é acceitavel a opinião geral, a saber que se devia elevar o senso na qualificação dos jurados, o que de nenhum modo tiraria ao jury o caracter popular.

Não deixaremos de tratar ainda de uma medida preventiva do crime. Diz FERri que a creação de um tribunal de honra provavelmente reduziria os duellos (Soc. pg. 432, n. 39, n. 4). Podemos generalisar, affirmando que a inefficacia da actual legislação processual, tornando dispendiosa a querela crime, onde 


\section{$-87-$}

quasi nunca se dá ao offendido a precisa satisfação (principalmente nos crimes de alçada de juizes togados) é outra fonte de crimes motivados pelo desejo natural de vingança. Sem fallar dos delictos de abuso de manifestação do pensamento pela imprensa, em que a excessiva tolerancia dos juizes togados é desculpada pelo escrupulo que ha de restringir a sacratissima liberdade de imprensa, encontramos as absolvições por delictos provadissimos de injurias verbaes ou publicadas em seç̧ões pagas de jornaes, que ninguem em bôa fé julgará que mereçam os favores dispensados á imprensa, que representa a opinião publica. Dizem os juizes que o offendido deve-se desforçar, si fôr um homem de brio, e não recorrer aos tribunaes.

Não é uma campanha em diametral opposição á movida contra o duello, aliás muito menos damnoso que as rixas: "difronti a questi reatti brutali um relativo miglioramento." (FERRI, Soc. pg. 433)? Examinem-se os archivos dos tribunaes de juizes togados, 'e ver-se-á quanto custa um processo de alçada, e por que futilidade foi annullado. Examinem-se os annaes do jury, e ver-se-á quantos enormes crimes foram nascidos da necessidade da vingança, ora por um sentimento natural, ora ainda por imposição da opinião publica!...

$$
*^{*} *
$$

Éstas observações foram por nós feitas sem plano preestabelecido, ao correr da penna, e tendo sempre em mente o desejo de provocar o exame do assumpto, que vae ficando em esquecimento, quando aos profissionaes cumpre sem descanço estudar este problema sempre presente nas sociedades. Nada tão desconsolador quanto vermos estacionar um ramo de estudos, 
remettendo-se os profissionaes ao que já está feito, e mantendo erros, que vão passando tradicionalmente.

A transformação radical por que passou a humanidade durante o ultimo seculo, impoz aos que se acham incumbidos do estudo dos meios de defender a ordem social, o dever de examinarem as condições actuaes de vida de cada povo, para que seja possivel lucta efficaz contra os elementos destruidores dos principios fundamentaes da organização da sociedade.

Eloquentes são os factos que escorçámos nestas poucas linhas, ao intento de mostrarmos o grande atrazo em que nos achamos e a imprudencia com que alguns espiritos, avidos de novidades, ou obcecados pela moda, vão acceitando doutrinas de nenhum modo fadadas a produzirem o fim colimado.

Nosso desejo era sómente dar o grito de alarma, e chamar a posto os que precisam entrar em lucta em defeza da ordem social.

Jỗo ArRuda. 